\title{
Clinical outcomes observation in stage IIB- IIIB cervical cancer treated by adjuvant surgery following concurrent chemoradiotherapy
}

\author{
Yong Li ${ }^{1}$, Zhiying Chen ${ }^{2}$, Xiang Wang ${ }^{2}$, Xiumei $\mathrm{Li}^{3}$, Jie Zhou ${ }^{2}$ and Yongchun Zhang ${ }^{2^{*}}$
}

\begin{abstract}
Background: To explore the feasibility of adjuvant surgery following concurrent chemoradiation therapy (CCRT) in stage IIB-IIIB (according to FIGO staging of 2009) cervical cancer and analyze risk factors of recurrence after surgery.

Methods: Forty-nine patients diagnosed with stage IIB-IIIB cervical cancer were reviewed retrospectively. We investigated the risk factors of recurrence after surgery using Chi-squared Test and further analyzed multiple factors affecting postoperative recurrence using the multi-factor logistic regression. Furthermore, the correlation of surgery outcomes (including operation time, bleeding, and hospitalization date and surgery complications) with the time which carried out between CCRT and completion surgery was analyzed.

Results: Tumor histology and residual tumor in the cervix were significantly associated with postoperative recurrence ( $P=0.014$ and $P=0.040$, respectively). Logistic regression analysis demonstrated that the independent risk factors of postoperative recurrence were age and residual tumor in the cervix $(P=0.017$ and $P=0.030$, respectively). Complications (operation time, bleeding, hospitalization date) were compared between patients with an interval with radiotherapy less than 6 weeks and patients with an interval longer than 6 weeks. There were statistical differences in the amount of bleeding and postoperative complications between the two groups ( $P=$ 0.019 and $P=0.044$, respectively).
\end{abstract}

Conclusion: CCRT combined with surgery for stage IIB-IIIB cervical cancer was feasible, reduced the rate of postoperative recurrence and surgery complications were tolerated.

Keywords: Cervical cancer, Concurrent chemoradiation, Surgery, Recurrence

\section{Background}

Cervical cancer is a worldwide major public health issue. It is the second most common malignancy in women and represents the third-leading cancer in women worldwide [1]. Approximately 500,000 new cases and 237,500 deaths of cervical cancer occur annually.

\footnotetext{
* Correspondence: summermed@126.com

${ }^{2}$ Department of Radiation Oncology, The Affiliated Hospital of Qingdao University, 16 Jiangsu Road, Qingdao 266003, P. R. China

Full list of author information is available at the end of the article
}

Advanced cervical cancer is not easy to control and has poor prognosis because of the lymph node metastasis or distant metastasis. Cisplatin- based concurrent chemoradiotherapy is the standard treatment for advanced cervical cancer, but the local recurrence rate after chemoradiotherapy is high and 5-year survival rate is only 50 to $65 \%$ [2]. In order to further improve the local control rate of cervical cancer and improve the 5-year survival rate, many scholars have explored the efficacy and safety of concurrent radiotherapy and chemotherapy

(c) The Author(s). 2021 Open Access This article is licensed under a Creative Commons Attribution 4.0 International License, which permits use, sharing, adaptation, distribution and reproduction in any medium or format, as long as you give appropriate credit to the original author(s) and the source, provide a link to the Creative Commons licence, and indicate if changes were made. The images or other third party material in this article are included in the article's Creative Commons licence, unless indicated otherwise in a credit line to the material. If material is not included in the article's Creative Commons licence and your intended use is not permitted by statutory regulation or exceeds the permitted use, you will need to obtain permission directly from the copyright holder. To view a copy of this licence, visit http://creativecommons.org/licenses/by/4.0/ The Creative Commons Public Domain Dedication waiver (http://creativecommons.org/publicdomain/zero/1.0/) applies to the data made available in this article, unless otherwise stated in a credit line to the data. 
combined with surgery in the treatment of advanced cervical cancer [3]. Some studies have reported that CCRT combined with surgery can improve local lesion control and overall survival, but the role of adjuvant surgery is still controversial, because these studies differ in disease stage, surgical scope, and form of CCRT (radiotherapy dose, internal irradiation or not, and type of chemotherapy) [4]. The purpose of this paper is to explore the feasibility of CCRT joint surgery in cervical cancer patients with IIB-IIIB period and retrospectively analyze the related factors of postoperative recurrence.

\section{Methods}

\section{Patients}

This study included 49 patients with biopsy proven cervical cancer between June 2006 and October 2012 was treated in department of Radiotherapy Center and Gynecology of the Affiliated Hospital of Qingdao University. The Institutional Review Board approved this study and informed consent was obtained. Inclusion criteria: a) Eastern Cooperative Oncology Group (ECOG) status was less than or equal to 1 ; b) International Federation of Gynecology and Obstetrics (FIGO) stages IIBIIIB cervical cancer through gynecological examination by two veteran gynecologic oncologists; c) All patients underwent a medical history, gynecological examination; punch biopsy, chest X-ray, pelvic magnetic resonance imaging (MRI) and transvaginal ultrasound (TVS). Exclusion criteria: a) Patients with serious heart, lung, liver or hematologic system disease; b) Patients with other cancer; c) Treatment was interrupted or radiotherapy did not reach the radical dose; d) Lost to follow-up or death from other causes.

\section{Concurrent chemoradiation therapy (CCRT)}

All patients completed the radical radiotherapy in department of Radiotherapy Center. Patients were immobilized with a body net in the supine position and underwent a computed tomography (CT) simulation scan (General Electric, Milwaukee WI, USA) with intravenous contrast, using $5 \mathrm{~mm}$ slice thickness. Simulation images extended from $\mathrm{L} 1$ to $5 \mathrm{~cm}$ below the ischial tuberosities. The gross tumor volume (GTV), clinical target volume (CTV) and planning target volume (PTV) were defined according to Radiation Therapy Oncology Group (RTOG) guidelines. The CTV-high risk included the GTV, parametrium, the upper part of the vagina to $3 \mathrm{~cm}$ below the tumor invasion, and metastasis lymph node. The CTV-low risk included the CTV-high risk and regional lymph nodes (common, external, internal iliac lymph nodes, obturator and presacral lymph nodes). The treatment planning was designed and computed using the Plato system version 2.7.5 (Varian, USA). The external radiation dose was $40-50$ Gy in $20-25$ fractions with 2 Gy per fraction using a linear accelerator (Trilogy, Varian, USA). And followed by high-dose-rate brachytherapy to $90 \%$ of the high-risk CTV was delivered with 30-40 Gy using an intracavity applicator (microSelectron-HDR Ir-192 set; Nucletron, Veenendaal, Netherlands). All patients received concomitant chemotherapy of cis-platinum $\left(40 \mathrm{mg} / \mathrm{m}^{2}\right)$ alone every week starting with external radiotherapy ( $4-5$ circles).

\section{Adjuvant surgery}

After reevaluated the relationship between cervix, bladder, rectum and parauterine tissue through gynecological examination and pelvic MRI, all patients underwent extrafascial hysterectomy with adnexectomy followed by CCRT. According to postoperative pathology, nine patients with invading $1 / 2$ of the cervical stroma recived 4 circles chemotherapy consisted of the association of cisplatinum $\left(100 \mathrm{mg} / \mathrm{m}^{2}\right)$ in combination with paclitaxel $\left(135 \mathrm{mg} / \mathrm{m}^{2}\right)$.

\section{Follow-up}

Patient follow-up was designed to be conducted every 3 months during the first 2 years and every 6 months over the next 3 years after surgery. The follow-up included gynecological examination, TVS, vaginal apical cytology, abdominal plevic and chest CT.

\section{Statistical analysis}

All data were performed using SPSS 20.0 (Chicago IL, USA). Quantitative data are expressed as the mean \pm standard deviation (S.D.). $X^{2}$ test or Fisher exact test was used to evaluate categorical variable. Groups were compared using Student's $t$-test.. Multivariate analysis of prognostic factors was performed with Cox proportional hazards regression. A $p<0.05$ was regarded as statistically significant.

\section{Results}

The correlations of major clinical/pathological factors and recurrence after CCRT and adjuvant surgery in LACC were summarized in Table 1 . Median age of 49 patients was 49 years (range 29-66) and there was statistically significant difference in age and recurrence of disease between two groups $(P=0.023)$. Median follow-up from the date of surgery was 76 months (range 29-129 months), and 5 patients died during follow-up. The 3year OS and 5-year OS were 95.9 and $89.8 \%$, respectively.

In early postoperative period ( $\leq 30$ days), 2 incomplete intestinal obstruction and 3 deep venous thrombosis were found. As far as long-term postoperative period (> 30 days), 3 complications were observed: 2 patients developed colorectal fistula and 1 patient showed pelvic pain. The average of operation time was $2.0 \pm 0.4 \mathrm{~h}$ 
Table 1 Correlations of major clinical/pathological factors and recurrence after CCRT and adjacent surgery in stage IIB-III cervical cancer

\begin{tabular}{|c|c|c|c|c|c|c|}
\hline \multirow[t]{2}{*}{ Factors } & & \multirow{2}{*}{$\begin{array}{l}\text { Number } \\
\text { (\%) }\end{array}$} & \multicolumn{2}{|c|}{ Recurrence } & \multirow[t]{2}{*}{$x^{2}$} & \multirow[t]{2}{*}{$p$} \\
\hline & & & No & Yes & & \\
\hline \multirow[t]{2}{*}{ Age } & $<50$ & $28(57.1)$ & 50 & 3 & 5. 168 & $0.023^{*}$ \\
\hline & $\geq 50$ & 21(42.9) & 13 & 8 & & \\
\hline \multirow[t]{2}{*}{ HPV infection } & No & $31(63.3)$ & 25 & 6 & 0.464 & 0.496 \\
\hline & Yes & 18(36.7) & 13 & 5 & & \\
\hline \multirow[t]{2}{*}{ Tumor diameters } & $\leq 4 \mathrm{~cm}$ & $20(40.8)$ & 14 & 6 & 1.107 & 0.293 \\
\hline & $>4 \mathrm{~cm}$ & 29(59.2) & 24 & 5 & & \\
\hline \multirow[t]{3}{*}{ Pathological differentiation } & High & $7(14.3)$ & 5 & 2 & 0.979 & 0.613 \\
\hline & Moderatly & $33(67.3)$ & 25 & 8 & & \\
\hline & Low & $9(18.4)$ & 8 & 1 & & \\
\hline \multirow[t]{2}{*}{ Pathologic subtypes } & Adenocarcinoma/mixed subtypes & $7(14.3)$ & 4 & 3 & 1.954 & 0.162 \\
\hline & SCC & $42(85.7)$ & 34 & 8 & & \\
\hline \multirow[t]{3}{*}{ FIGO stage } & $\| \mathrm{B}$ & $41(83.7)$ & 32 & 9 & 0.657 & 0.720 \\
\hline & $\| \mathrm{A}$ & $1(2.0)$ & 1 & 0 & & \\
\hline & $\| I I B$ & $7(14.3)$ & 5 & 2 & & \\
\hline \multirow[t]{3}{*}{ Microscopic residual } & No & $27(55.1)$ & 20 & 7 & 8.920 & $0.012^{*}$ \\
\hline & Disease invading less than $50 \%$ of the myometrium & $13(26.5)$ & 13 & 0 & 8.920 & $0.012^{*}$ \\
\hline & Disease invading more than $50 \%$ of the myometrium & $9(18.4)$ & 5 & 4 & & \\
\hline
\end{tabular}

CCRT concurrent chemoradiotherapy, HPV human papillomavirus, FIGO International Federation of Gynecology and Obstetrics, SCC squamous cell carcinoma, ${ }^{*} P<0.05$

(range 1.2-3.1 h) and blood loss during the surgery was $133.5 \pm 66.7 \mathrm{~mL}$ (range $50-400 \mathrm{~mL}$ ). The average hospital stay was $9.4 \pm 2.1$ days (range 6-15 days). The relationship between the time to start operation after CCRT and blood loss during the surgery, hospital stay and postoperative complication were analyzed furthermore (Table 2). Although blood loss during the surgery, hospital stay and postoperative complication in $>6$ weeks group were less than that in $\leq 6$ weeks group, only blood loss during surgery and postoperative complication were closely related with the time to start operation after CCRT (F = 5.866, $P=0.019 ; \mathrm{F}=4.056, P=0.044)$.

After the combination of CCRT and surgery, recurrence of disease was observed in 12 (22.4\%) patients, which were distributed as follows: 9 local recurrences and 3 distant metastases (1 lung metastasis and 2 bone metastases). After adjuvant surgery, 27 patients (55.1\%) showed a complete response to CCRT treatment, and 22 cases $(44.9 \%)$ showed a microscopic residual disease (9 cases with disease invading more than $50 \%$ of the myometrium and 13 cases with disease invading less than $50 \%$ of the myometrium). There was statistically significant difference in recurrence of disease and microscopic residual $(P=0.012)$. On multivariate analysis showed both age and microscopic residual were highly correlated with recurrence of disease (Table 3$)(P=0.017$ and $P=$ 0.030 , respectively). Although there was not statistically significant difference in tumor diameters and recurrence of disease, tumor diameters was highly correlated with microscopic residual on further analysis (Table 4).

\section{Disscussion}

Local and distant recurrence is the main reason for the failure of treatment of locally advanced cervical cancer. Studies have reported that CCRT can improve the local control of lesions, progression-free survival and total survival in patients with locally advanced cervical cancer. Some researchers $[5,6]$ believe that the control of local

Table 2 The evaluation of operation time

\begin{tabular}{|c|c|c|c|c|c|c|c|c|c|}
\hline \multirow[t]{2}{*}{ Groups } & \multirow{2}{*}{$\begin{array}{l}\text { Operation } \\
\text { time } \\
\text { (h) }\end{array}$} & \multirow[t]{2}{*}{$p$} & \multirow{2}{*}{$\begin{array}{l}\text { Bleeding } \\
(\mathrm{mL})\end{array}$} & \multirow[t]{2}{*}{$p$} & \multirow{2}{*}{$\begin{array}{l}\text { Hospital } \\
\text { stay } \\
\text { (day) }\end{array}$} & \multirow[t]{2}{*}{$p$} & \multicolumn{2}{|c|}{ Complications } & \multirow[t]{2}{*}{$p$} \\
\hline & & & & & & & No & Yes & \\
\hline$\leq 6$ weeks & $1.812 \pm 0.376$ & 0.942 & $147.41 \pm 78.377$ & $0.019^{*}$ & $9.740 \pm 2.141$ & 0.225 & 20 & 7 & $0.044^{*}$ \\
\hline$>6$ weeks & $1.944 \pm 0.368$ & & $115.70 \pm 43.425$ & & $9.050 \pm 2.081$ & & 21 & 1 & \\
\hline
\end{tabular}


Table 3 Multivariate analysis of recurrence after CCRT and adjacent surgery in stage IIB-III cervical cancer

\begin{tabular}{lll}
\hline Parameters & $\boldsymbol{P}$ & $\operatorname{Exp}(\boldsymbol{B}) \mathbf{9 5 \%} \mathbf{C l}$ \\
\hline Age & $0.017^{*}$ & $25.086(1.777 \sim 354.179)$ \\
HPV infection & 0.271 & $3.633(0.365 \sim 36.167)$ \\
Tumor diameters & 0.765 & $0.715(0.079 \sim 6.476)$ \\
Pathological differentiation & 0.487 & $3.168(0.123 \sim 81.769)$ \\
Pathologic subtype & 0.339 & $0.205(0.008 \sim 5.296)$ \\
FIGO stage & 0.252 & $0.080(0.001 \sim 6.008)$ \\
Residual cancer & $0.030^{*}$ & $0.038(0.002 \sim 0.725)$ \\
Constant & 0.544 & \\
\hline
\end{tabular}

CCRT concurrent chemoradiotherapy, ${ }^{*} P<0.05$

lesions can improve the surgical resection rate. At present, there are few studies on adjuvant surgery, which is controversial for further reducing recurrence rate and improving prognosis. In this study, a total of 49 patients with locally advanced cervical cancer were included. The lesions all shrank to different degrees after CCRT treatment, among which 18 patients showed significant improvement in paratactic infiltration. About 3-9 weeks after CCRT treatment, all patients underwent extrafascial hysterectomy and bilateral adnexectomy, and the incidence of postoperative complications was $16.3 \%$, similar to $19.8 \%$ in the previous study [7]. 9 cases of patients were proved to be local recurrence with pathologically, and distant metastasis was observed in 3 patients. The recurrence rate $(22.4 \%)$ was little higher compared with the previous work, which 192 IIB-IVA stage cervical cancer patients was included. The recurrence rate in our study is slightly higher than CCRT joint surgery (16.7\%), however, there was a decrease compared to CCRT alone (31.7\%). Maybe it was the small sample size that led to such different results.

This study showed that pathological cancer residue was closely related to recurrence, and multivariate analysis of variance showed that cancer residue was an independent risk factor for postoperative recurrence, which was consistent with previous research results $[7,8]$. Further study found that residual carcinoma associated with preoperative lesions in diameter, suggesting that patients with tumor lesions of large diameter were more likely to relapse. The higher recurrence rate may be associated with the lack of oxygen in the center of tumors, which leading to a decrease in the sensitivity of tumor cells to radiation and weakens the efficacy of radiotherapy [9]. In this study, postoperative pathological types were significantly correlated with postoperative recurrence. The recurrence rate of patients with simple squamous cell carcinoma was lower than other pathological types. This may because squamous cell carcinoma has higher radiosensitivity than other pathological types [10]. In this study, multivariate analysis of variance showed that age was also an independent risk factor for postoperative recurrence, which may be related to difference in hormone and immune levels in different age groups. However, it is still controversial whether age is related to recurrence and prognosis. Other previous studies [11] have pointed out that the degree of tumor differentiation can affect the sensitivity of tumor cells to radiation. However, this study did not suggest that the degree of differentiation of cervical cancer is related to local recurrence. This may be related to the small number of included cases and the uneven proportion of the degree of differentiation and a large sample study is needed for further validation. In this study, the incidence of postoperative complications was $16.3 \%$, mainly due to mild myelosuppression and gastrointestinal reactions. The 2 cases of postoperative incomplete intestinal obstruction and intestinal fistula recovered after conservative treatment. By contrast to the previous studies (12.8-19.8\%), the complication rate was within an acceptable range in our study $[12,13]$. In addition, in this study, the time between the CCRT and surgery was compared in different group. By comparing the operative time, bleeding volume and postoperative complications, the interval $>6$ weeks group was better than the group with interval $\leq 6$ weeks and the result was statistically different. By analyzing the reason, the tissue was still in a state of hyperemia and edema after chemoradiotherapy, so the risk of bleeding and infection after operation in short-interval

Table 4 The relationship between macroscopic residual and clinical/pathological factors

\begin{tabular}{|c|c|c|c|c|c|}
\hline \multirow{2}{*}{$\begin{array}{l}\text { clinical/pathological } \\
\text { factors }\end{array}$} & & \multicolumn{2}{|c|}{ Macroscopic residual } & \multirow[t]{2}{*}{$x^{2}$} & \multirow[t]{2}{*}{$p$} \\
\hline & & No & Yes & & \\
\hline \multirow[t]{2}{*}{ Tumor diameters } & $\leq 4 \mathrm{~cm}$ & 18 & 2 & 14.337 & $<0.001^{*}$ \\
\hline & $>4 \mathrm{~cm}$ & 9 & 20 & & \\
\hline \multirow[t]{3}{*}{ Pathological differentiation } & High & 4 & 3 & 0.017 & 0.992 \\
\hline & Moderately & 18 & 5 & & \\
\hline & Low & 5 & 4 & & \\
\hline \multirow[t]{2}{*}{ Pathologic subtype } & Adenocarcinoma/mixed subtypes & 3 & 4 & 0.086 & 0.769 \\
\hline & SCC & 24 & 18 & & \\
\hline
\end{tabular}


increased. Therefore, appropriately extending the time between CCRT and surgery can reduce intraoperative bleeding and facilitate postoperative recovery.

This study retrospectively analyzed the cervical cancer patients with IIB-IIIB stage who accepted extra-fascial hysterectomy and bilateral adnexectomy hysterectomy surgery after CCRT. The postoperative recurrence rate decreased than pure CCRT treatment and there was no obvious increase in postoperative complications. The joint is expected to improve the local control rate of locally advanced cervical cancer patients and improve the long-term curative effect.

This retrospective analysis is affected by many factors, and the sample size of this study needs to be expanded or better prospective study to explore the feasibility of this program.

\section{Conclusions}

CCRT combined with surgery for stage IIB-IIIB cervical cancer was feasible, reduced the rate of postoperative recurrence and surgery complications were tolerated.

\section{Abbreviations}

CCRT: Concurrent chemoradiation therapy; GTV: Gross tumor volume; CTV: Clinical target volume; PTV: Planning target volume; RTOG: Radiation Therapy Oncology Group

\section{Acknowledgements}

Not applicable.

\section{Authors' contributions}

$Y C$, conception: $Y$ and $Y C$, design of the work: $X M$ and J, the acquisition, analysis; $Y$ drafted the work; $Z Y$. and $X$, interpretation of data. All authors have read and approved the manuscript, and ensure that this is the case.

\section{Funding}

Not applicable.

\section{Availability of data and materials}

The datasets used and/or analyzed during the current study are available from the corresponding authors upon reasonable request.

\section{Declarations}

\section{Ethics approval and consent to participate}

This study was approved by the Affiliated Hospital of Qingdao University (the Institutional Review Board). Written informed consent for publication was obtained from all participants.

\section{Consent for publication}

Not applicable.

\section{Competing interests}

The authors declare that they have no competing interests.

\section{Author details}

'Department of Gynecology, The Affiliated Hospital of Qingdao University, Shandong 266003 Qingdao, China. ${ }^{2}$ Department of Radiation Oncology, The Affiliated Hospital of Qingdao University, 16 Jiangsu Road, Qingdao 266003, P. R. China. ${ }^{3}$ Department of Abdominal Ultrasound, The Affiliated Hospital of Qingdao University, Shandong 266003 Qingdao, China.
Received: 11 October 2020 Accepted: 5 April 2021

Published online: 21 April 2021

\section{References}

1. Wei LC, Wang N, Shi M, Liu JY, Li JP, Zhang Y, et al. Clinical outcome observation of preoperative concurrent chemoradiotherapy/radiotherapy alone in 174 Chinese patients with local advanced cervical carcinoma. OncoTargets Ther. 2013;6:67-74. https://doi.org/10.2147/OTT.S39495.

2. Chereau $E, C D L H$, Ballester $M$, Monnier $L$, Rouzier R, Touboul $E$, et al. the role of completion surgery after concurrent radiochemotherapy in locally advanced stages IB2-IIB cervical cancer. Anticancer Res. 2013;33(4):1661-6.

3. Houvenaeghel G, Lelievre L, Gonzague-Casabianca L, Buttarelli M, Moutardier V, Goncalves A, et al. Long-term survival after concomitant chemoradiotherapy prior to surgery in advanced cervical carcinoma. Gynecol Oncol. 2006;100(2):338-43. https://doi.org/10.1016/j.ygyno.2005.08. 047.

4. Malzoni M, Spina V, Perniola G, Aleandri V, Mossa B, luele T, et al. Laparoscopic surgery in treatment of stage Illb cervical cancer after neoadjuvant chemotherapy. A case report and review of the literature. Eur $J$ Gynaecol Oncol. 2003;24(5):393-7.

5. Ota T, Takeshima N, Tabata T, Hasumi K, Takizawa K. Adjuvant hysterectomy for treatment of residual disease in patients with cervical cancer treated with radiation therapy. Br J Cancer. 2008;99(8):1216-20. https://doi.org/10.1 038/sj.bjc.6604619.

6. Classe JM, Rauch P, Rodier JF, Morice P, Stoeckle E, Lasry S, et al. Groupe des Chirurgiens de Centre de Lutte Contre le C: surgery after concurrent chemoradiotherapy and brachytherapy for the treatment of advanced cervical cancer: morbidity and outcome: results of a multicenter study of the GCCLCC (Groupe des Chirurgiens de Centre de Lutte Contre le Cancer). Gynecol Oncol. 2006;102(3):523-9. https://doi.org/10.1016/j.ygyno.2006.01. 022.

7. Sun L, Sheng X, Jiang J, Li X, Liu N, Liu Y, et al. Surgical morbidity and oncologic results after concurrent chemoradiation therapy for advanced cervical cancer. Int J Gynaecol Obstet. 2014;125(2):111-5. https://doi.org/10.1 016/j.ijgo.2013.07.041.

8. Hirakawa M, Nagai Y, Toita T, Kudaka W, Inamine M, Ogawa K, et al. Highrisk group for locoregional recurrence in patients with stage IB-IIB squamous cell carcinoma of the cervix treated with concurrent chemoradiotherapy. Anticancer Res. 2011;31(4):1437-41.

9. Gray LH, Conger AD, Ebert M, Hornsey S, Scott OC. The concentration of oxygen dissolved in tissues at the time of irradiation as a factor in radiotherapy. Br J Radiol. 1953;26(312):638-48. https://doi.org/10.1259/ 0007-1285-26-312-638.

10. Ferrandina G, Margariti PA, Smaniotto D, Petrillo M, Salerno MG, Fagotti A et al. Long-term analysis of clinical outcome and complications in locally advanced cervical cancer patients administered concomitant chemoradiation followed by radical surgery. Gynecol Oncol. 2010;119(3): 404-10. https://doi.org/10.1016/j.ygyno.2010.08.004.

11. Kim YH, Chung WK, Jeong JU, Cho IJ, Yoon MS, Song JY, et al. Evaluation of prognostic factors for the parotid Cancer treated with surgery and postoperative radiotherapy. Clin Exp Otorhinolaryngol. 2019.

12. Mariagrazia D, Anna F, Gabriella F, Francesco F, Daniela S, Giuseppe D, et al. Preoperative chemoradiotherapy in locally advanced cervical cancer: longterm outcome and complications. Gynecol Oncol. 2005;99(3 Suppl 1):S16670. https://doi.org/10.1016/j.ygyno.2005.07.074

13. Trimbos JB, Franchi M, Zanaboni F, Velden J, Vergote I. State of the art' of radical hysterectomy; current practice in European oncology centres. Eur J Cancer. 2004;40(3):375-8. https://doi.org/10.1016/j.ejca.2003.09.017.

\section{Publisher's Note}

Springer Nature remains neutral with regard to jurisdictional claims in published maps and institutional affiliations. 